\title{
ESTUDO SOBRE A PERDA DE MUDAS ARBÓREAS PLANTADAS NO SISTEMA VIÁRIO DA CIDADE DE SÃO PAULO
}

\author{
Renier Marcos Rotermund ${ }^{1}$; Viviane Pisano Motta ${ }^{2}$; Vinícius de Souza Almeida ${ }^{3}$
}

\section{RESUMO}

O objetivo da pesquisa foi de analisar de forma quantitativa e qualitativa, as questões relativas à mortalidade de mudas plantadas no sistema viário, por uma equipe contratada pela SVMA no âmbito do Programa de Arborização Urbana. Os resultados obtidos indicam um volume de perdas acima da média observada em estudos correlatos realizados em outros países. A partir dos resultados obtidos, discussão sobre os resultados, observações de campo e levantamentos bibliográficos, procurou-se traçar diretrizes e propostas de ações com o objetivo de reduzir as perdas em plantios de mudas de árvores.

Palavras chave: arborização urbana; mortalidade de mudas; manejo da floresta urbana.

\section{A LOSS ASSESSMENT OF YOUNG TREES PLANTED ON SÃO PAULO STREETS}

\section{ABSTRACT}

The aim of this research was to analyze quantitatively and qualitatively, the issues of mortality of young trees planted in the road system by a team hired by São Paulo Citie’s Environmental Department under the Urban Forestry Program. The results indicate a volume of losses above the average observed in related studies conducted in other countries. From the results obtained, discussion of the results, field observations and literature surveys, we tried to set guidelines and proposals for actions aimed at reducing losses in plantations of young trees.

Keywords: urban forestry; young tree mortality, urban forest management. 


\section{INTRODUÇÃO}

A floresta urbana possui papel fundamental na manutenção e melhoria da qualidade ambiental das cidades, existindo uma vasta literatura que trata de benefícios providos por ela. Entre eles destacam-se: melhoramento climático (LOMBARDO, 1985), benefícios à saúde humana (JACKSON, 2003), redução da poluição atmosférica (LULEY, et al. 2002), controle de enchentes (SILVA, 2008), maior valor social e econômico em comparação aos espaços não arborizados (MCPHERSON, et al. 2008) e contribuição das áreas verdes para a redução da violência de uma localidade (FREIRE 2005).

A diminuição da cobertura arbórea das cidades passa a ser, neste contexto, um grave problema social-ambiental, refletindo diretamente na qualidade de vida dos cidadãos. A Associação Norte Americana "American Forests" (2010) concluiu, após um estudo em mais de 20 cidades de seu país (Estados Unidos da América), que a sobrevida média de uma árvore plantada em áreas urbanas centrais é de apenas 13 anos, idade em que a árvore ainda não desempenha seus serviços ecossistêmicos em plenitude. Rossetti et al (2009) consideram as calçadas de um sistema viário um ambiente de conflito. O vandalismo e a depredação das mudas é explicado pelo fato de que parte da população não entende o limite entre bem público, comum ou privado, achando que o que está na calçada não é de ninguém ou que as árvores interferem as construções de seus comércios ou de suas casas. Para Bond (2005), enquanto as taxas de mortalidade não forem consideradas, as projeções de cobertura arbórea serão muito otimistas em termos de melhoria ambiental esperadas para o local, mas os resultados esperados não serão alcançados. O desconhecimento destas perdas inviabiliza qualquer projeção, bem como a avaliação dos resultados obtidos.

Visto que a cobertura arbórea da cidade de São Paulo é insuficiente para o provimento satisfatório dos citados benefícios, vêm-se realizando esforços no sentido de aumenta-la com o plantio de novas árvores. Com a aprovação da emenda n³0 à lei orgânica do município de São Paulo, ficou instituído o Programa de Metas “Agenda 2012”, onde um dos compromissos estabelecidos pela gestão 2009 a 2012 foi o plantio de 800.000 mudas. A lei municipal n¹4.186 de 2006, que instituiu o Programa Municipal de Arborização Urbana definiu que a gestão de áreas verdes e da arborização seja feita com metodologia sistematizada de manejo e acompanhamento. Neste sentido, informações sobre o número de mudas perdidas, as causas destas perdas, ou mudas que se desenvolveram de maneira inadequada são relevantes no planejamento e nas ações para o aumento da cobertura arbórea em espaços urbanos.

A presente pesquisa trabalha com um número amostral de poucas mudas se comparada ao volume de árvores plantadas pelo programa. Porém, considerando a falta de pesquisa sobre o tema, é importante à medida que apresenta informações, propõe medidas para mitigar estas perdas e aponta questões que podem ser investigadas em pesquisas futuras mais aprofundadas.

\section{MATERIAIS E MÉTODOS}

Durante o período de 21 meses acompanhou-se o desenvolvimento de 79 mudas desde o plantio e em 4 outras vistorias posteriores. As mudas foram plantadas na região de Santo Amaro, zona sul da cidade de São Paulo. Para cada uma das mudas analisadas foi elaborada uma ficha com informações relevantes para a sua identificação, características do plantio e informações sobre seu desenvolvimento. As fichas de acompanhamento continham informações que podem ser categorizadas em três tipos: informações pré-plantio (sobre o local), informações de plantio e informações de manutenção e desenvolvimento.

As informações pré-plantio referem-se às características da via onde as mudas foram plantadas, tais como: logradouro, localização do plantio, largura do passeio, distância de outros equipamentos, presença e tipo de 
fiação, intensidade de fluxo de pedestres, tipo predominante de fluxo de veículos, entre outros. As informações de plantio abrangem as características e condições iniciais das mudas no momento de plantio, tais como: espécie, perímetro do tronco à altura de 1,30m, altura da muda, condição geral da muda e do torrão e também sobre a qualidade do plantio realizado (se houve destorroamento, se a muda foi plantada reta, bem tutorada, etc.). As informações de Manutenção e Desenvolvimento referem-se às características das mudas após o seu plantio, bem como eventuais danos à ela e ao tutoramento. Foram verificados, entre outros: perímetro do tronco a altura de 1,30m (PAP), altura da muda, condição geral da muda, quebra de partes da muda, morte ou ausência da muda, ramo ladrão, danos ao tutor, amarrio, entre outros.

Na primeira vistoria, foram preenchidos os dados referentes ao local e as informações pré plantio e de plantio. Nas vistorias subseqüentes, foram feitos apontamentos acerca das informações de manutenção e desenvolvimento. A muda foi considerada perdida quando constatada a sua morte ou quando ela estava ausente, ou seja, a cova aonde foi plantada se encontrava vazia. Realizou-se também o acompanhamento fotográfico de cada muda possibilitando a observação mais detalhada de seu desenvolvimento ao longo do tempo.

As discussões aqui apresentadas são provenientes, não apenas da pesquisa em si, como também da observação e da experiência adquirida pela equipe responsável pela execução do Programa de Arborização Urbana em diversas subprefeituras da Zona Sul de São Paulo durante os últimos anos, além de consulta à literatura relacionada ao tema.

\section{RESULTADOS E DISCUSSÕES}

A partir do acompanhamento do desenvolvimento das mudas, foram obtidos os seguintes resultados em relação à morte ou ausência das mesmas:

Três meses após o plantio, na primeira vistoria, apenas uma das mudas estava ausente (1,27\%). Durante as vistorias seguintes, verificou-se uma progressão destas perdas. Na segunda vistoria, constatou-se que a taxa acumulada de perdas foi de 7,59\% (6 mudas), na terceira vistoria realizada observou-se a perda acumulada de 12,66\% (10 mudas) e na quarta e última a perda constatada foi de 20,25\% (16 mudas) do total de mudas plantadas 21 meses mais cedo. A Figura 1 demonstra tais resultados.

Não foram consideradas nesta contagem as mudas vivas que deveriam ser substituídas, seja por estarem muito danificadas, seja por apresentarem desenvolvimento inadequado. A partir de uma vistoria com a finalidade de identificar quais mudas não teriam condições de serem mantidas, chegou-se a conclusão de que pelo menos 23 deveriam ser substituídas por mudas novas, o que elevaria as perdas para $49,3 \%$.
Observa-se que há um aumento maior de perdas a partir do $3^{\circ}$ mês após os plantios. Isto pode ser explicado pelo fato de que, durante o período imediatamente após o plantio, as condições de suporte a essa muda estão mantidas. A partir de então, pela falta de manutenção regular, essas condições de suporte começam a deteriorar e diversos problemas começam a surgir e se acumular, tais como a perda do amarrio, dano ao tutoramento, erosão de canteiros, tombamento da muda, entre outros. Toda essa soma de fatores negativos que se acumulam inicialmente pode gerar um crescimento maior da taxa de perdas de árvores nos meses subseqüentes, caso não haja manutenção que corrija os problemas. Importante mencionar que, durante o período em que estas mudas foram monitoradas, não houve manutenção das mesmas. Estes resultados indicam uma mortalidade maior do que a verificada por Miller e Miller (1991) em estudos realizados em três comunidades de Wisconsin. Esses estudos revelaram uma taxa de mortalidade de cerca de $25 \%$ das mudas no período de 4 anos, sendo que aproximadamente $50 \%$ dessas perdas ocorriam no primeiro ano. Após a consolidação dessas mudas admite- 
se um cenário de perda de indivíduos que varia entre 1 a

$2 \%$. Na Figura 2 é possível visualizar as perdas de mudas verificadas por Miller e Miller (1991)

\section{Mudas perdidas (\%) ao longo do Tempo}

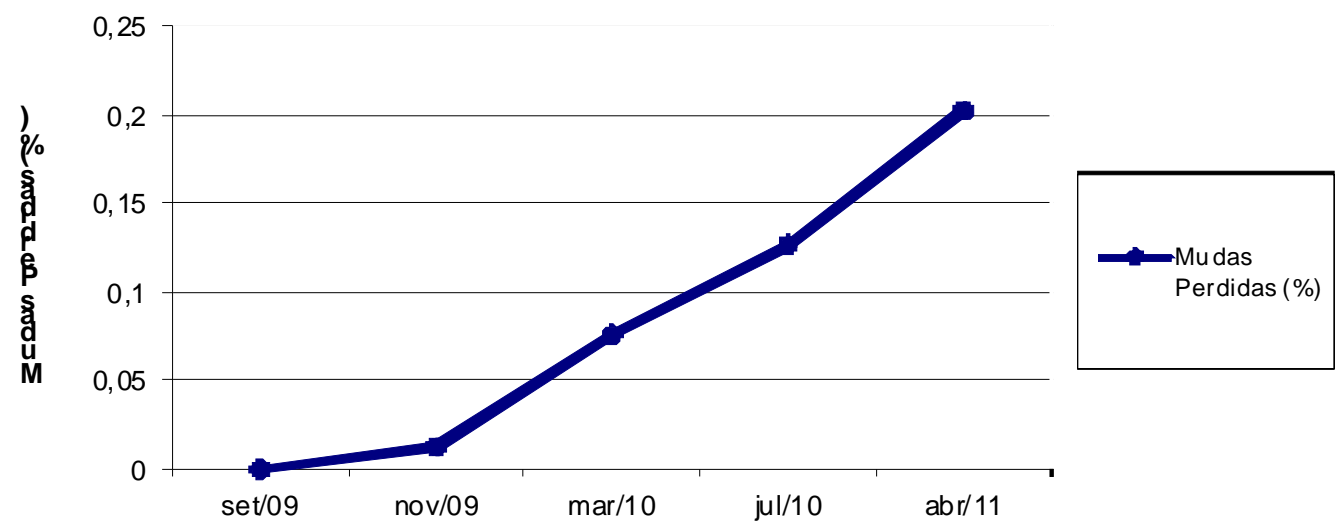

Data da Vistoria

Figura 1 - Evolução da perda de mudas de árvores ao longo de um período de 21 meses de observação.

Figure 1 - Evolution of the loss of young tree over a period of 21 months of observation.

Acumulado (\%) de Remoções

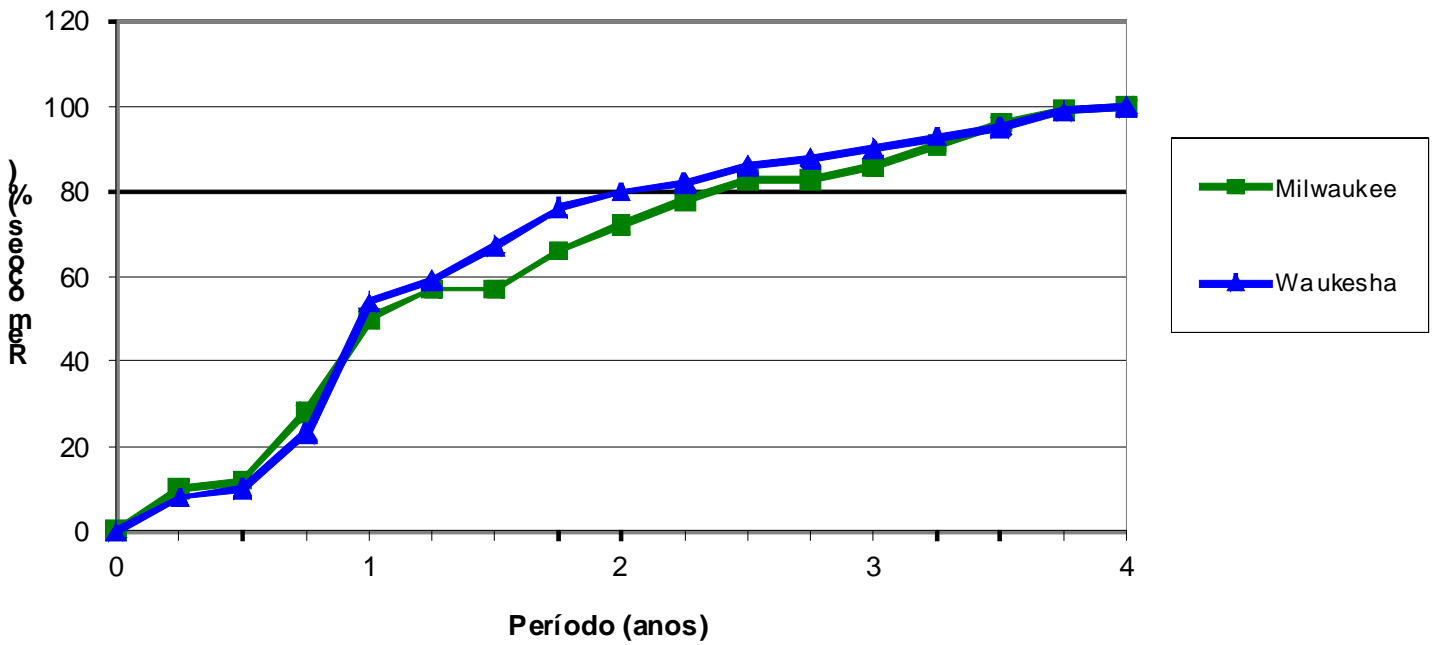

Fonte: Miller e Miller (1991)

Figura 2 - Evolução da perda de mudas de árvores em Wisconsin, Estados Unidos, durante os primeiros quatro anos após o plantio.

Figure 2 - Evolution of the loss of young trees in Wisconsin, United States, during the first four years after planting. 
Bond (2005), analisando diferentes trabalhos de arborização nos EUA, Canadá e Inglaterra, verificou que as perdas variaram entre 3 e $9 \%$ ao ano para os quatro primeiros anos, sendo a perda média estimada entre 5 e $7 \%$. Após o $4^{\circ}$ ano, essas perdas oscilaram entre 0,5 a $2 \%$ ao ano segundo o mesmo autor. Ao juntarmos os cenários de perdas dos primeiros 4 anos ao dos 26 anos subseqüentes teremos uma variação entre $25 \%$ nas melhores condições a $60 \%$ nas piores condições. Os dados referentes a fatores relacionados a taxa de mortalidade anual de mudas pode ser verificado na Tabela 1.

Tabela 1 - Taxas médias de mortalidade de mudas obtidas a partir da compilação de estudos relacionados ao tema em paises do hemisfério norte.

Table 1 - Average rates of mortality of young trees obtained from the compilation of studies related to the topic in the northern hemisphere countries.

\begin{tabular}{c|c|l}
\hline \multicolumn{2}{c}{ Período de Consolidação da Muda (de 1 a 4 anos após o plantio) } \\
\hline Taxa de Mortalidade Anual & \multicolumn{1}{c}{ Fatores de Seleção da Taxa } \\
\hline Alta & 7 a $9 \%$ & $\begin{array}{l}\text { Clima quente e seco, pessoal de plantio não treinado, plantio não monitorado, estoque de } \\
\text { mudas de máqualidade, locais de plantio estressantes, ausencia de cuidados pós plantio, } \\
\text { ausência de envolvimento da comunidade. }\end{array}$ \\
\hline Média & 5 a $7 \%$ & \\
\hline Baixa & 3 a 5\% & $\begin{array}{l}\text { Clima temperado e úmido, pessoal de plantio treinado, monitoramento do plantio, mudas } \\
\text { de qualidade, locais não estressantes, cuidados pós plantio, envolvimento da comunidade. }\end{array}$ \\
\hline
\end{tabular}

Período Pós Consolidação da Muda (4 a 30 anos após o plantio)

\begin{tabular}{c|c|l}
\hline \multicolumn{2}{|c|}{ Taxa de Mortalidade Anual } & \multicolumn{1}{c}{ Fatores de Seleção da Taxa } \\
\hline Alta & $2 \%$ & $\begin{array}{l}\text { Clima quente e seco, falta de adequação entre local e muda, muda de má qualidade, falta de } \\
\text { treinamento e supervisão no plantio, muitos locais de estresse para as plantas, ausência de } \\
\text { envolvimento da comunidade. }\end{array}$ \\
\hline Média & $1 \%$ & \\
\hline Baixa & $0,5 \%$ & $\begin{array}{l}\text { Clima temperado e úmido, boa adequação entre local e muda, muda com estrutura de } \\
\text { raízes adequada, treinamento e supervisão no plantio, locais de pouco estresse para as } \\
\text { plantas, envolvimento da comunidade. }\end{array}$ \\
\hline
\end{tabular}

Identificar quantas mudas foram perdidas devido a vandalismo é um procedimento difícil. Nas observações realizadas para o presente trabalho, a maioria das mudas perdidas estava ausente no momento da vistoria, não sendo possível averiguar qual foi o motivo que levou a sua perda. Seria importante saber se a muda morreu por problemas de adaptação ao local e depois foi removida, ou se ela foi vandalizada e removida viva. Todavia, agressões causadas diretamente pelo ser humano foram observadas em várias mudas, tais como quebra de ponteiro, quebra de ramo ou até do tronco. Isto nos leva a crer que o número de mudas perdidas por vandalismo é grande.

A partir de dados sobre manutenção de mudas realizado na região da Capela do Socorro, São Paulo, foram constatadas perdas ainda maiores de mudas. Foram realizadas nos meses de abril e maio de 2011 contagens de mudas mortas, inutilizadas e ausentes. De um universo 
de 7338 mudas plantadas em diferentes momentos, foram perdidas 2720. A porcentagem de perdas variou conforme o local e a data do último plantio de reposição até o momento da contagem. O plantio mais antigo, realizado em janeiro de 2010 teve 53,01\% de perda e os mais recentes, de outubro de 2010, já contava com perdas que variaram de $27,78 \%$ a $17,82 \%$, dependendo do local. A maioria destes plantios foi executada em calçadas de vias bastante transitadas e as mudas utilizadas tinham geralmente DAP em torno de $2 \mathrm{~cm}$. Praticamente não foram observadas mudas mortas, o que poderia indicar algum problema relacionado ao seu não pegamento. Ou a muda estava ausente ou ela estava severamente danificada, sendo então removida. Os números aqui apresentados foram obtidos a partir de uma contagem simples, não realizada de maneira absolutamente cuidadosa, e que certamente contém imprecisões. Entretanto ilustra em que escala de perdas pode-se estar trabalhando.

A partir da experiência contínua com o trabalho de plantio e manutenção de mudas, pôde-se observar que a perda é menos frequente em mudas mais robustas. Isto foi verificado também em relação as mudas acompanhadas. O número de mudas perdidas foi maior nos grupos com PAP (perímetro a altura do peito) menores, do que as mudas com PAP maior, como pode ser visualizado no gráfico abaixo (Figura 3).

\section{Mudas Perdidas por Classe de PAP}

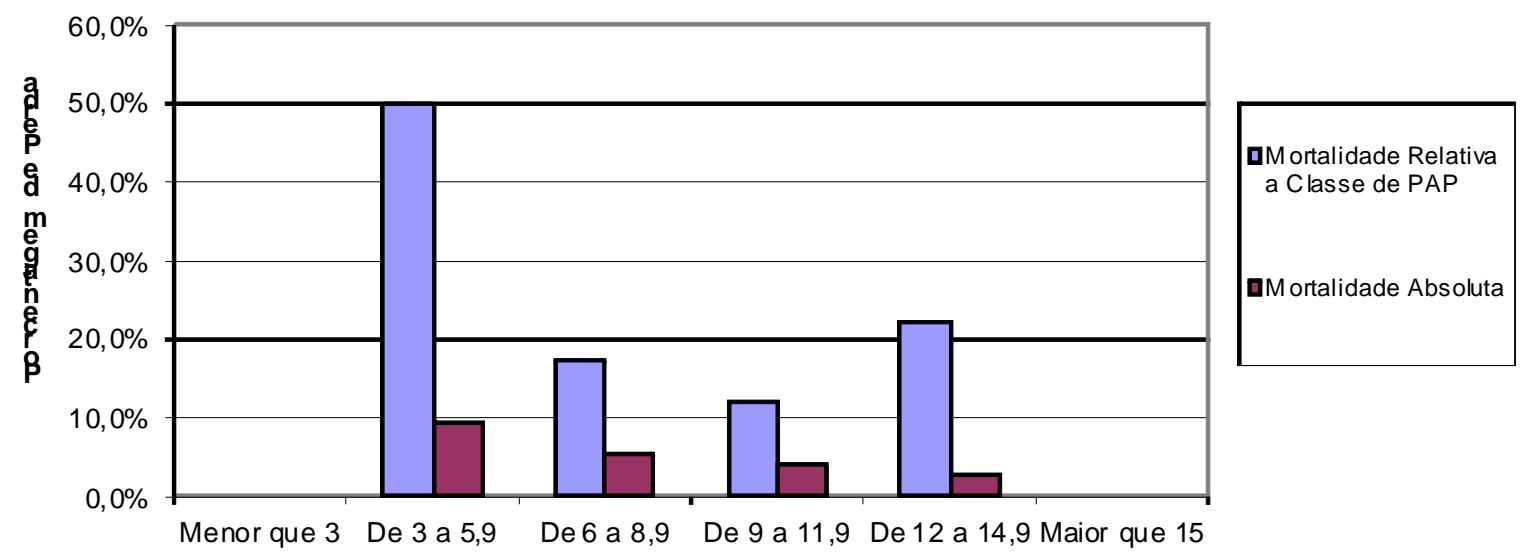

Classes de PAP (cm)

Figura 3 - Relação entre Perímetro a Altura do Peito e mudas perdidas observadas no grupo de mudas acompanhadas na pesquisa. Figure 3 - Relationship between Diameter at Breast Height and mortality observed in the group of young trees monitored in the assessment.

Ainda que o principal problema pareça estar relacionado a questão do vandalismo, cabe aqui uma análise em relação a qualidade das mudas utilizadas nos plantios acompanhados. Diversos problemas foram relatados, que se não chegam a resultar na perda da muda, com certeza afetam significativamente o seu desenvolvimento. A muda pode simplesmente não se desenvolver, permanecendo anos a fio sem crescimento. Pode perecer após um certo periodo. Ou então com sorte, após algum tempo recupera-se e inicia o seu crescimento. De qualquer maneira a probabilidade dessa muda ser perdida é maior do que uma muda em bom estado.

Os principais problemas observados durante os trabalhos de plantio estavam relacionados ao porte e ao sistema 
radicular. Sobre o porte, conforme já discutido, as mudas eram muitas vezes pequenas e frágeis para o ambiente de calçada em sistema viário. Em outras situações, foram utilizadas mudas com DAP adequado, que no entanto apresentavam-se estioladas. Nestes casos, que podem ser visualizados na Figura 4, na medida em que a copa se desenvolve e torna-se mais pesada, pode ocorrer o tombamento da muda ou a quebra do tronco.

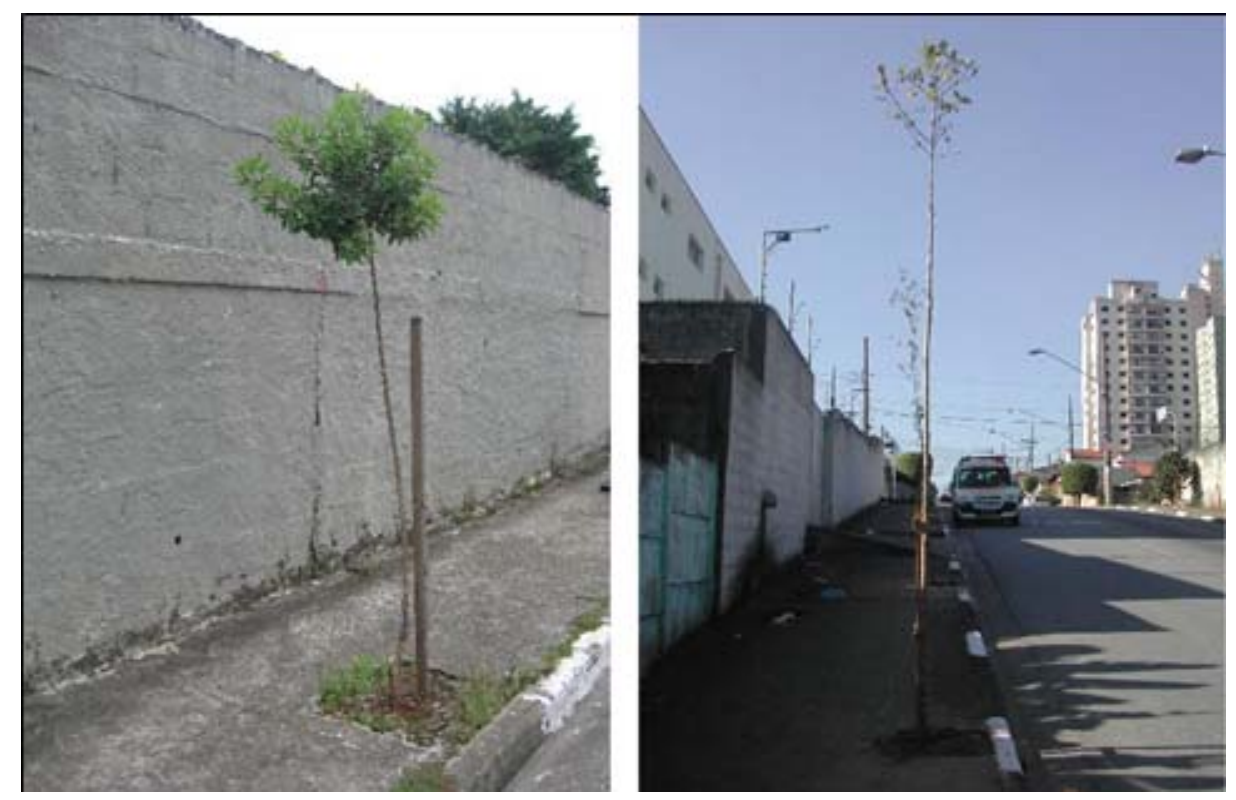

Figura 4 - À esquerda, muda Aroeira Brava (Lithraea molleoides) com porte inadequado (pequena e frágil) para plantio em calçada. À direita, muda estiolada de Guanandi (Calophyllum brasiliensis)

Figure 4 - At left, a young Aroeira Brava tree (Lithraea molleoides) with inadequate size (small and fragile) for sidewalk planting. At right, a stunted young Guanandi tree (Calophyllum brasiliensis).

Sobre a formação de raízes, muitas das mudas não tinham sistema radicular formado dentro do pote, indicando que a extração era recente e que não havia sido dado o tempo necessário para a sua recuperação. Outra situação encontrada foi a de mudas cujas raízes haviam sido seccionadas, provavelmente por já terem ultrapassado o volume do pote e enraizando no solo fora deste. Em ambos os casos, o volume do torrão geralmente se desfazia com facilidade. Tais problemas com relação às raízes das mudas podem ser visualizados na Figura 5.

O tutoramento, a proteção da muda e o amarrio são intervenções que precisam ser bem executadas e mantidas integras. O amarrio ou tutoramento ausentes, feitos em posição inadequada, soltos ou mesmo danificados, favorecem a quebra do tronco ou injúrias deste por atrito. Isto foi observado em diversas mudas, principalmente após a $2^{\mathrm{a}}$ vistoria, onde amarrio e/ou tutoramento já estavam prejudicados pela falta de manutenção.

As lesões atingem muitas vezes um perímetro significativo do tronco, formando calos e comprometendo o desenvolvimento das mudas chegando até a sua morte. A solução para tais problemas pode ser conseguida com trabalhos contínuos de manutenção, a fim de que amarrio, tutor e protetor estejam íntegros e bem fixados.

Outra lesão observada com frequência é ocasionada pelo transporte das mudas. O excesso de mudas na caçamba ou a não proteção adequada do tronco e da copa, faz com que estas já cheguem danificadas ao seu destino. Aqueles que manuseiam e transportam as mudas precisam ser orientados ou acompanhados para evitar danos. Um transporte descuidado pode levar a perda de todo um lote de mudas. Os danos mais comumente observados são os de lesão de caule e quebra de ramos. O manejo não 
cuidadoso do torrão é particularmente danoso, muitas vezes levando ao seu completo destorroamento, e que pode resultar na morte da muda após o plantio.
Finalmente, as mudas precisam ser protegidas de vento e insolação excessivas durante a viagem até o local de plantio, especialmente se esta se der em longas distâncias.

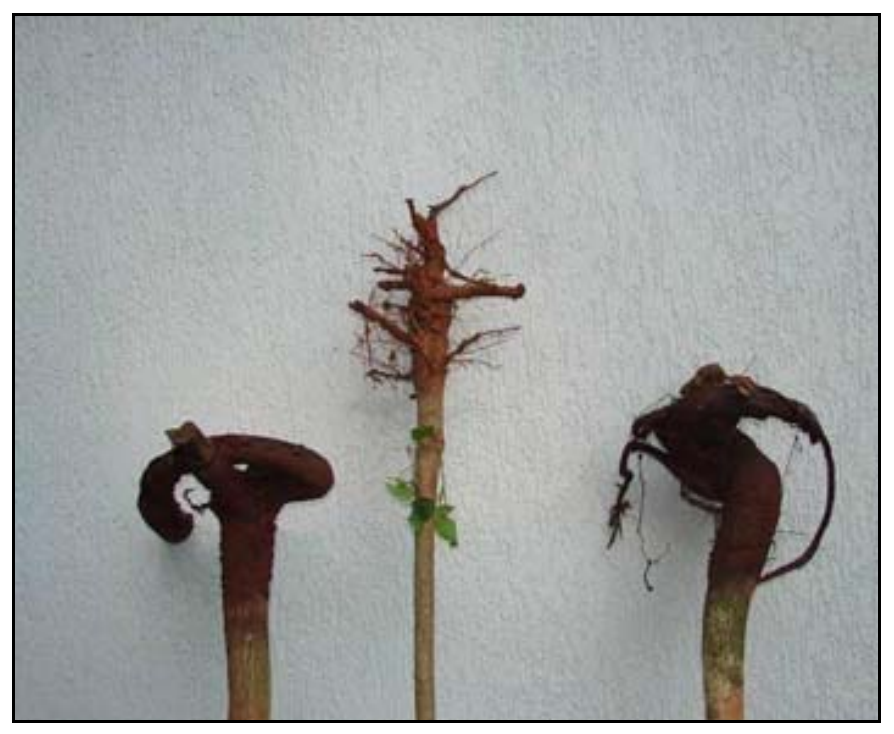

Figura 5 - Mudas com sistema radicular mal formado ou seccionado que haviam sido recém envasadas.

Figure 5 - Young trees with malformed or sectioned roots that had just been bottled.

\section{CONCLUSÕES E RECOMENDAÇÕES}

A consolidação de novas árvores depende de um trabalho complexo, que envolve não apenas o plantio, mas toda a cadeia de produção e manutenção e principalmente da aceitação e engajamento da população em relação à arborização.

Os resultados aqui apresentados mostram claramente que existe uma perda significativa de mudas plantadas. Estas perdas são muito superiores as observadas por Miller e por Bond e podem ser ao longo do tempo extremamente altas se considerarmos o seu acúmulo. Neste sentido, sendo constatadas, as suas razões precisam ser trabalhadas a fim de não se por todo um árduo trabalho a perder.

Como já discutido, a arborização é um elemento fundamental para a qualidade ambiental e social em uma cidade. Este entendimento, embora já assimilado por alguns grupos da sociedade, tanto do governo quanto da sociedade civil, ainda não é compartilhado com uma parcela muito significativa da população. Se a comunidade não enxergar na arborização este papel, ela não dará a devida importância em sua ampliação e conservação. As árvores serão vistas mais como um incômodo por sua "sujeira”, pelo seu risco de queda, do que pelos benefícios que nos são hoje tão valiosos. É deste ponto que o trabalho de plantio, assim como todas as outras atividades de manejo da floresta urbana precisam partir. De uma visão compartilhada por toda a sociedade em relação a floresta urbana, na qual reconheça-se a sua importância e necessidade, assim como a dos trabalhos para a sua conservação, desenvolvimento e crescimento.

A manutenção periódica e freqüente deve ser considerada como prioridade em qualquer programa de plantio. Ela é vital para o desenvolvimento adequado das mudas até que estas se consolidem, pois permite a correção em tempo adequado de eventuais problemas. A manutenção periódica faz com que o zelo pela planta seja visível, estimulando as pessoas a também zelar por ela e constrangendo atos de agressão. Recomendamos que esta manutenção preventiva tenha uma periodicidade maior no 
primeiro ano, com intervalos de três meses e podendo ser mais espaçados se a avaliação demonstrar que a muda está em bom processo de desenvolvimento. Em condições ideais, além da manutenção preventiva, as manutenções corretivas deveriam ocorrer sempre que algum problema for detectado.

O uso de mudas robustas e bem formadas, com DAP igual ou superior a 5 e alturas acima de 2,5 a 3 metros em áreas com grande circulação de pessoas deveria ser a regra. Além de minimizar as perdas por vandalismo, provoca uma mudança imediata na paisagem, levando as pessoas à percepção da arborização. É fato que mudas maiores tornam o processo de plantio mais oneroso e demorado, alem de poder apresentar problemas decorrentes do processo de extração e adaptação ao local. Mesmo assim, entendemos que é mais vantajoso o uso destas mudas. Aqui cabe reforçar que não se trata apenas de porte, mas de uma muda saudável, com sistema radicular bem desenvolvido, em suma, de boa qualidade. Por fim, lembramos que do ponto de vista da muda, a atividade de plantio, desde a sua extração ou mudança de ambiente, até a sua inserção em um local geralmente hostil ao seu desenvolvimento é um evento estressante, sendo natural alguma perda. Esta deve ser contabilizada no planejamento para que os resultados esperados sejam atingidos, para que o recurso seja suficiente e para que não faltem mudas para reposição das que morrerem. A perda de mudas pode e deve ser reduzida, mas em momento algum, desprezada.

\section{REFERÊNCIAS}

BOND, JERRY. The Significance of Young Urban Tree Mortality on State Implementation Plan (SIP) Planning. Davey Resource Group: United States of America, 2005. 5 p. (Factsheet). Disponível em: www.urbantrees.org/policymakers/factsheets/mortality.pdf Acessado em 20/09/2010

FREIRE, Helena B. Sistema De Lazer e Violência Urbana: Estudo Da Relação No Município De Piracicaba. 2005. 64p. Dissertação (Mestrado em Fitotecnia). Escola Superior de Agricultura "Luiz de Queiroz"- Universidade de São Paulo. São Paulo.

JACKSON, Laura E. The Relationship of Urban Design to Human Health and Condition. Landscape and Urban Planning: United States of America, v. 64 p. 191-200, 2003.

LOMBARDO, Magda A. Ilha de calor nas metrópoles: o exemplo de São Paulo. Editora HUCITED: São Paulo, 1985. 210 p.

LULEY, CHRISTOPHER J.; BOND, JERRY. A Plan to integrate management of urban trees into air quality planning: A Report to North East State Foresters Association. Davey Resource Group: United States of America, 2002. 69 p. Disponível em:

http://www.urbantrees.org/policymakers/studies/IntegrateTrees_LuleyBond.pdf Acessado em 29/08/2010.

MCPHERSON, E. GREGORY; SIMPSON, JAMES R.; XIAO, QINGFU; WU, CHUNXIN. Los Angeles 1-Million Tree Canopy Cover Assessment. USDA Forest Services: United States of America, 2008. 52 p. Disponível em: http://www.fs.fed.us/psw/publications/documents/psw_gtr207/psw_gtr207.pdf Acessado em: 20/09/2010.

MILLER, Randal H.; MILLER, Ronald W. 1991. Planting survival of selected street tree taxa. Journal of Arboriculture: United States of America, v. 17, n. 7, p.185-191, 1991.

MILLER, Robert W. Urban forestry, planning and managing urban greenspaces. $2^{\text {nd }}$ ed. Prentice Hall: United States of America, 1997. 502 p.

ROSSETI, Adriana N.; PELEGRINO, Paulo R. M.; TAVARES, Armando R. O Espaço Metropolitano na Cidade de São Paulo e a Interface com a Arborização: Aspectos da Transformação Socioeconômica, do Sítio Físico e da Proteção de Vegetais de Porte Arbóreo. Revista da Sociedade Brasileira de Arborização Urbana, São Paulo: v. 4, n. 1 p.21-28, 2009. 
SILVA, L. F. Interceptação Da Chuva Nas Espécies De Sibipiruna (Caesalpinia pluviosa) e Tipuana (Tipuana tipu 0. kuntze). 2008. 60 p. Dissertação (Doutrado em Agronomia). Escola Superior de Agricultura "Luiz de Queiroz"-

Universidade de São Paulo. São Paulo.

SÂO PAULO (Município). Lei Municipal 14.186 de 04 de Agosto de 2006. Institui o Programa Municipal de Arborização Urbana. Diário Oficial do Município de São Paulo, São Paulo, 05 ago. 2008.

Páginas Eletrônicas:

AMERICAN FORESTS. Setting Urban Tree Canopy Goals. United States of America, 2010. Disponível em: http://www.americanforests.org. Acessado em 13/11/2010

AGENDA 2012. Programa de Metas da Cidade de São Paulo. Disponível em http://www.agenda2012.com.br/cidadesustentavel. Acessado em 02/02/2011 